\title{
Increased Resistance Against Citrus Canker Mediated by a Citrus Mitogen-Activated Protein Kinase
}

\author{
Maria Luiza Peixoto de Oliveira, ${ }^{1}$ Caio Cesar de Lima Silva, ${ }^{1}$ Valéria Yukari Abe, ${ }^{1}$ \\ Marcio Gilberto Cardoso Costa, ${ }^{2}$ Raúl Andrés Cernadas, ${ }^{1}$ and Celso Eduardo Benedetti ${ }^{1}$ \\ ${ }^{1}$ Laboratório Nacional de Biociências (LNBio), Centro Nacional de Pesquisa em Energia e Materiais (CNPEM), CP6192, \\ CEP 13083-970, Campinas, SP, Brazil; ²Departamento de Ciências Biológicas, Universidade Estadual de Santa Cruz, \\ Ilhéus, BA, Brazil
}

Submitted 30 April 2013. Accepted 14 June 2013.

\begin{abstract}
Mitogen-activated protein kinases (MAPK) play crucial roles in plant immunity. We previously identified a citrus MAPK (CsMAPK1) as a differentially expressed protein in response to infection by Xanthomonas aurantifolii, a bacterium that causes citrus canker in Mexican lime but a hypersensitive reaction in sweet oranges. Here, we confirm that, in sweet orange, CsMAPK1 is rapidly and preferentially induced by $X$. aurantifolii relative to Xanthomonas citri. To investigate the role of CsMAPK1 in citrus canker resistance, we expressed CsMAPK1 in citrus plants under the control of the $P R 5$ gene promoter, which is induced by Xanthomonas infection and wounding. Increased expression of CsMAPK1 correlated with a reduction in canker symptoms and a decrease in bacterial growth. Canker lesions in plants with higher CsMAPK1 levels were smaller and showed fewer signs of epidermal rupture. Transgenic plants also revealed higher transcript levels of defenserelated genes and a significant accumulation of hydrogen peroxide in response to wounding or $X$. citri infection. Accordingly, nontransgenic sweet orange leaves accumulate both CsMAPK1 and hydrogen peroxide in response to $X$. aurantifolii but not $X$. citri infection. These data, thus, indicate that CsMAPK1 functions in the citrus canker defense response by inducing defense gene expression and reactive oxygen species accumulation during infection.
\end{abstract}

Mitogen-activated protein kinases (MAPK) are evolutionarily conserved components of sophisticated signaling cascades or mechanisms used by the cells to transduce extracellular stimuli to intracellular responses. Usually, in these signal transduction pathways, MAPK are activated by MAPK kinases (MAP2K or MEK) that were previously activated by MAPKK kinases (MAP3K or MEKK) in sequential phosphorylation reactions (Melech-Bonfil and Sessa 2010; Rodriguez et al. 2010;

Current address for M. L. P. de Oliveira:U.S. Horticultural Research Laboratory, U.S. Department of Agriculture, Agricultural Research Service, 2001 South Rock Road, Fort Pierce, FL 34945, U.S.A.

Current address for R. A. Cernadas:Department of Plant Pathology and Plant-Microbe Biology, Cornell University, Ithaca, NY 14853, U.S.A.

Corresponding author:C. E. Benedetti; Telephone:+1 5519 35121111; Fax:+1 5519 35121006; E-mail address:celso.benedetti@ lnbio.org.br

* The $\boldsymbol{e}$-Xtra logo stands for "electronic extra" and indicates that Figure 1 appears in color online.

(C) 2013 The American Phytopathological Society
Sinha et al. 2011; Vilela et al. 2010). In many plant species, MAPK are known to play crucial roles in plant immunity and to mediate responses to many abiotic stresses, such as cold, drought, and wounding (Jonak et al. 1996; Mizogushi et al. 1996; Ligterink et al. 1997; Seo et al. 2007; Sinha et al. 2011).

In response to microbial attack, the MAPK signaling cascade is activated upon the perception of microbe-associated molecular patterns (MAMPs), which, in turn, initiates a coordinated basal defense or immune response characterized by the expression of pathogen-responsive genes, production of reactive oxygen species (ROS), and deposition of callose and lignin at sites of infection (Chisholm et al. 2006). On the other hand, successful microbes overcome these defense responses by deploying a variety of effector molecules that ultimately suppress the immune response (Jones and Dangl 2006).

As initial components of the immune response, MAPK function as serine and threonine kinases that phosphorylate a wide range of protein targets, including members of the WRKY family of transcription factors responsible for the activation of downstream effector genes (Chisholm et al. 2006; Sinha et al. 2011). An example of direct physiological targets of MAPK is the tobacco WRKY factor 8 (WRKY8) that is phosphorylated by the MAPK SIPK, NTF4, and WIPK, involved in innate immunity and regulation of cell death triggered by pathogens (Ishihama et al. 2011; Ren et al. 2006). The MAPK-dependent activation of WRKY8 increases the DNA binding affinity of WRKY8 to its cognate W-box sequences leading to the expression of defense-related genes (Ishihama et al. 2011).

Citrus spp. are susceptible to the bacterial pathogens Xanthomonas citri and Xanthomonas aurantifolii, the causal agents of citrus canker, an economically important disease characterized by raised pustules on the tissue epidermis (Brunings and Gabriel 2003). Different forms of the disease were characterized; the Asiatic canker (or pathotype A) being the most aggressive and widespread. Asiatic canker is caused by $X$. citri, which infects almost any commercial variety. In contrast, $X$. aurantifolii pathotype $\mathrm{C}$ is limited to the Mexican lime alone and induces a hypersensitive response (HR) in sweet oranges (Brunings and Gabriel 2003; Cernadas et al. 2008).

We investigated the differential pathogenicity exhibited by $X$. citri and $X$. aurantifolii pathotype $\mathrm{C}$ in sweet oranges by transcriptional analyses of leaves infected with these bacteria (Cernadas et al. 2008). We found that $X$. citri preferentially modulates a set of genes associated with canker development, including those implicated in cell-wall remodeling, cell division, and expansion. On the other hand, $X$. aurantifolii induces

1190 / Molecular Plant-Microbe Interactions 
a substantial number of genes associated with a basal defense response consistent with the establishment of an HR through MAPK signaling (Cernadas and Benedetti 2009; Cernadas et al. 2008). In fact, a citrus MAPK (CsMAPK1) related to the tobacco SIPK and WIPK, induced by salicylic acid (SA) and wounding, respectively, was preferentially induced by $X$. $a u$ rantifolii at the very early stage of infection (Cernadas et al. 2008). In addition, $X$. aurantifolii induced the expression of WRKY factors similar to pepper WRKY2 and rice OsWRKY71, implicated in resistance against Xanthomonas vesicatoria and Xanthomonas oryzae, respectively (Liu et al. 2007a; Oh et al. 2006). A MAPKK similar to the SIPK/WIPK/NTF4 activator NtMEK2 (Liu et al. 2007b; Takahashi et al. 2007), and numerous enzymes of the oxidative burst response were also up-regulated preferentially by $X$. $a u$ rantifolii in the onset of infection (Cernadas et al. 2008). These results pointed out the CsMAPK1 signaling as an interesting executor candidate of the $X$. aurantifolii-triggered HR in sweet orange. In contrast, we noted that $X$. citri suppresses this pathway within a few hours after bacterial infection as revealed by the downregulation of defense-related genes at $48 \mathrm{~h}$ after infiltration (Cernadas et al. 2008).

Considering that MAPK have been implicated in plant defense by boosting hydrogen peroxide production and induction of defense gene expression (Ren et al. 2002, 2006; Sinha et al. 2011), we sought to test whether CsMAPK1 could coordinate a defense response against $X$. citri in sweet oranges. Therefore, we expressed CsMAPK1 in Troyer citrange plants under the control of a Xanthomonas-inducible promoter. The results of this study show that the enhanced expression of CsMAPK1 correlates with a decrease in $X$. citri growth and a reduction in canker symptoms. Moreover, we demonstrate that increased expression of CsMAPK1 correlates with the overexpression of defense-related genes and accumulation of hydrogen peroxide. These results suggest that CsMAPK1 contributes to the defense against these Xanthomonas pathogens through activation of defense-related genes and production of ROS and that $X$. citri overcomes these CsMAPK1-dependent defense responses during the onset of infection.

\section{RESULTS}

\section{CsMAPK1 is preferentially induced}

in the defense response of Citrus sinensis to $X$. aurantifolii.

Previously, we found that the citrus expressed sequence tag CX073386, encoding a MAPK, was specifically up-regulated in the resistance response of sweet orange leaves to $X$. aurantifolii (Cernadas et al. 2008). To further investigate the role of this gene in plant defense, we cloned the corresponding fulllength cDNA from sweet orange and named CsMAPK1. CsMAPK1 encodes a nearly 43-kDa MAPK of the serine and threonine protein kinase subfamily bearing a single kinase do-
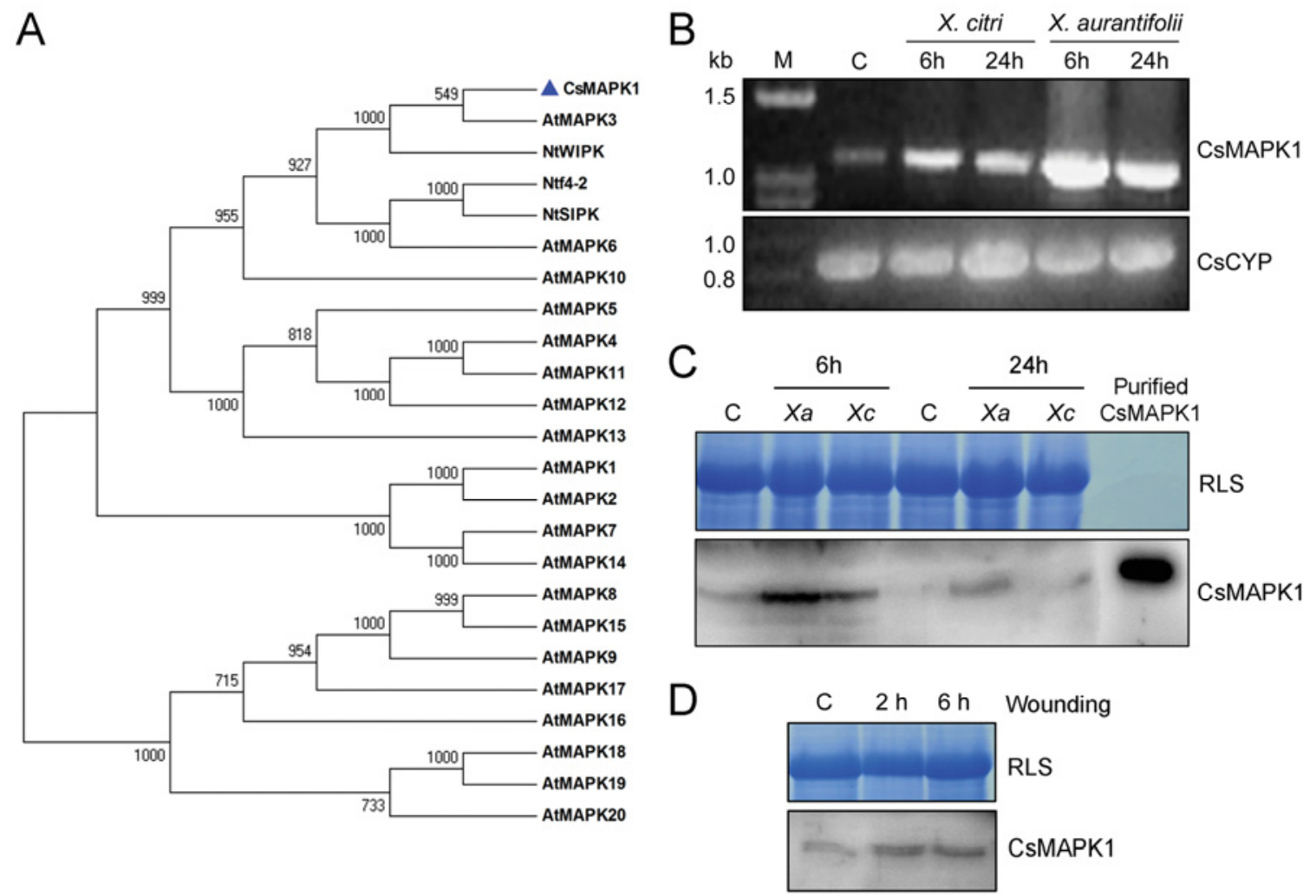

Fig. 1. CsMAPK1 is a single kinase-domain mitogen-activated protein kinases (MAPK) preferentially induced in the defense response of Citrus sinensis to Xanthomonas aurantifolii. A, Phylogenetic tree of MAPK of Citrus sinensis (CsMAPK1), Nicotiana tabacum (Nt), and Arabidopsis thaliana (At). Amino acid sequences were aligned using ClustalX and a maximum likelihood phylogenetic analysis was generated using the MEGA4 program based on the neighbor-joining method. Bootstrap values (above 50\%) from 1,000 replicates are indicated at each branch. B, Semiquantitative reverse-transcription polymerase chain reaction analysis of CsMAPK1 expression in sweet orange leaves challenged with X. citri, X. aurantifolii, or mock control (C). The CsMAPK1 mRNA is preferentially induced in the incompatible interaction between sweet orange and X. aurantifolii at 6 and $24 \mathrm{~h}$ after bacterial inoculation (approximately $10^{4}$ cells). The citrus gene encoding the CsCYP protein was used as internal control for equal cDNA inputs, and the molecular marker (M) is indicated. C, Western blot analysis of sweet orange proteins extracted from leaves inoculated with X. citri $(X c)$, X. aurantifolii $(X a)$, or noninoculated (C) at 6 and $24 \mathrm{~h}$ after infiltration. As positive control, the purified 6xHis-CsMAPK1 protein (approximately $43 \mathrm{kDa}$ ) was detected with an antiserum raised against CsMAPK1 (purified CsMAPK1). D, Western blot analysis of sweet orange proteins extracted from leaves at 2 and $6 \mathrm{~h}$ after wounding. For panels $\mathrm{C}$ and $\mathrm{D}$, equal protein loads were verified with Coomassie brilliant blue, included above the corresponding blots. RLS corresponds to the ribulose-1,5-bisphosphate carboxylase large subunit. 
main. Phylogenetic analyses revealed that CsMAPK1 belongs to Group A of MAPK (MAPK Group 2002) (Fig. 1A). The CsMAPK1 shares a strong similarity (96\% of identity) with PtrMAPK, a Poncirus trifoliata MAPK that enhances drought tolerance when overexpressed in tobacco (Huang et al. 2011). Besides, CsMAPK1 belongs to the same phylogenetic group with Arabidopsis AtMAPK3 and tobacco WIPK and SIPK kinases, the former regulates environmental stresses responses and was also involved in the resistance against the necrotrophic fungi Botrytis cinerea (Galletti et al. 2011; Mizoguchi et al. 1996). In particular, the WIPK and SIPK are components of MAPK cascades implicated in the tomato resistance against Xanthomonas vesicatoria (Melech-Bonfil and Sessa 2011). With these evidences, we work on the hypothesis that CsMAPK1 is a functional ortholog of AtMAPK3, WIPK, and SIPK (Fig. 1A).

To confirm our microarray data and to test whether CsMAPK1 is associated with the incompatible interaction, we infiltrated sweet orange leaves with $X$. aurantifolii and $X$. citri and analyzed the mRNA and protein levels of CsMAPK1 at 6 and $24 \mathrm{~h}$ after bacterial inoculation. The results show that CsMAPKI is induced in response to both $X$. citri and $X$. aurantifolii infections; however, the levels of CsMAPK1 mRNA are dramatically higher in the incompatible interaction at both 6 and $24 \mathrm{~h}$ after infection (Fig. 1B). Consistent with this, the CsMAPK1 polypeptide accumulated at higher levels in response to $X$. aurantifolii than $X$. citri infection at $6 \mathrm{~h}$ postin-
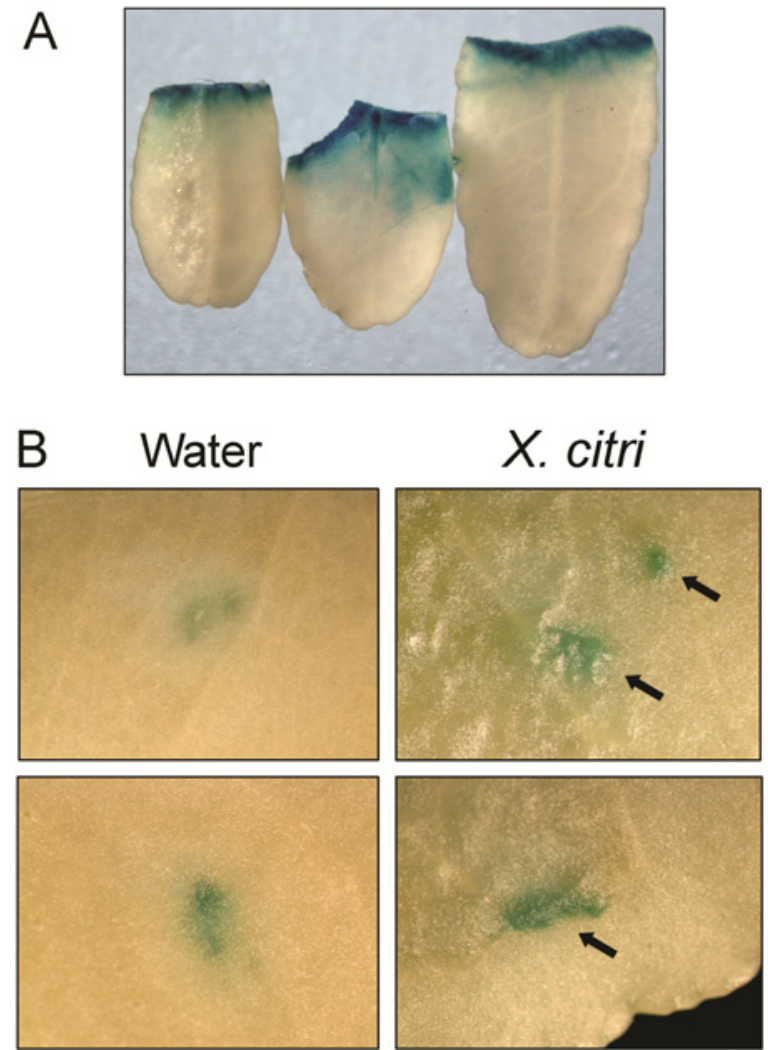

Fig. 2. The citrus $P R 5$ promoter is induced by wounding and Xanthomonas citri infection. A, $\beta$-Glucuronidase (GUS) activity in leaves of three independent PR5::GUS reporter plants in response to wounding. Leaves were chopped with a razor blade and were immediately immersed in the GUS assay buffer for histological detection of GUS activity (blue areas in the vicinity of the wounds). B, GUS activity in leaves of reporter plants 10 days after bacterial infiltration (approximately $10^{5}$ cells). GUS staining is observed in developing pustules (arrows), whereas in leaf sectors infiltrated with water, GUS staining was restricted to the vicinity of the pinprick. oculation. In addition, CsMAPK1 protein was barely detected in leaves infiltrated with $X$. citri at $24 \mathrm{~h}$ postinfection, indicating that this kinase is involved in the incompatible interaction (Fig. 1C).

Since BLAST analyses revealed that CsMAPK1 is $83 \%$ identical to the NtWIPK, we asked whether the protein would also accumulate upon wounding (Seo et al. 1995). The results revealed that CsMAPK1 is only slightly induced by wounding in sweet orange leaves 2 or $6 \mathrm{~h}$ after the treatment (Fig. 1D). Taken together, these data support the idea that CsMAPK1 plays a role in the early defense response triggered by $X$. aurantifolii in sweet orange.

\section{Generation of transgenic citrus lines expressing CsMAPK1} under the control of a Xanthomonas-induced promoter.

Considering that $X$. citri suppresses the host basal defenses at early stages of infection (Cernadas et al. 2008) and that $C s M A P K 1$ is strongly induced during the incompatible interaction, we sought to investigate the role of CsMAPK1 overexpression in canker development, using the pathogenesis-related PR5 gene promoter, which is rapidly induced after $X$. citri infiltration (Cernadas et al. 2008). Therefore, we generated two constructs, PR5::CsMAPK1 and PR5::uidA (control), and used them to transform citrus model plants Troyer citrange (Citrus sinensis $\times$ Poncirus trifoliata). We selected Troyer plants because they are susceptible to $X$. citri, efficient to transform, and demand shorter regeneration periods.

To test the responsiveness of the PR5 promoter to bacterial infection, three independent $\beta$-glucuronidase (GUS) reporter plants were infiltrated with suspensions of $X$. citri. We found that the $P R 5$ promoter is not only induced by $X$. citri infection but also upon wounding (Fig. 2A). In leaf sectors infiltrated with $X$. citri, the $P R 5:: G U S$ activity was predominantly detected in the developing pustules, whereas, in leaf sectors infiltrated with water, the PR5::GUS activity was restricted to the vicinity of the pinpricks (Fig. 2B). These results thus show that the PR5 promoter is capable of driven the expression of a reporter gene in response to both local wounding and canker pustules development after $X$. citri infiltration.

\section{Accumulation of CsMAPK1 hampers $X$. citri growth and decreases canker symptoms in Troyer plants.}

To test the function of the PR5 promoter-induction of CsMAPK1 in response to $X$. citri, we first analyzed the expression levels of CsMAPK1 by quantitative polymerase chain reaction $(\mathrm{PCR})$ in four independent transgenic Troyer plants (CsMAPK1-3, CsMAPK1-13, CsMAPK1-15, and CsMAPK118) carrying the $P R 5: \because C s M A P K 1$ cassette after bacterial infiltration. The results were consistent with the previous GUS reporter experiments and demonstrate that all four CSMAPKI transgenic lines accumulate higher levels of the CsMAPK1 mRNA at 6 and $24 \mathrm{~h}$ after bacterial infiltration (Fig. 3A). In fact, the PR5 promoter was capable of driving significantly higher expression of $C s M A P K 1$ compared with its native promoter upon $X$. citri challenge (Fig. 3A). In agreement with this, we also observed higher accumulation of CsMAPK1 protein in transgenic leaves infiltrated with $X$. citri (Fig. 3B). In addition, our data revealed that the CsMAPK1 protein accumulation was also higher in the transgenic lines in response to wounding, relative to the control plants (Fig. 3C).

To know whether the enhanced expression of CsMAPK1 would affect canker symptom development, we sprayed the lower side of transgenic and control leaves with a suspension of $X$. citri $\left(10^{6}\right.$ cells per milliliter). We observed that canker symptoms started to appear within 35 days after spraying and that the CsMAPK1-13 plant showed the most significant reduction in canker symptoms (Fig. 3D, upper panel). Neverthe- 
less, canker symptoms in CsMAPK1-3, CsMAPK1-15, and CsMAPK1-18 lines were also relatively less severe than in control plants based on the number, morphology, or pigmentation, alone or in combination, of the developed pustules. Moreover, we noticed no rupture of the epidermis in pustules developed on the CsMAPK1-13 line, even after 60 days after bacterial infection. On the other hand, canker pustules developed in the CsMAPK1-3 and CsMAPK1-15 lines were similar to those of line 13 but bigger (Fig. 3D, lower panel). Pustules developed in line 18 were also smaller and fewer than in control plants. However, in contrast with line 13, CsMAPK1-3, CsMAPK1-15, and CsMAPK1-18, showed epidermal rupture later during the infection (Fig. 3D, lower panel).

When leaves were infiltrated with a suspension of $X$. citri (approximately $10^{3}$ cells), we also observed a reduction in the number of rising pustules in the transgenic lines as compared with the control (Fig. 3E). However, epidermal rupture was observed in all transgenic lines, indicating that under more severe conditions of infection, CsMAPK1 overexpression appears to be less effective to inhibit pustule formation.

Next, we performed Western blots to analyze the protein levels of CsMAPK1 on leaves of CsMAPK1-13 infiltrated with $X$. citri that showed reduced canker lesions (Fig. 3D and E). We found that the CsMAPK1-13 line expresses CsMAPK1 not only early $(6 \mathrm{~h})$ after infiltration but, also, later (40 days postinoculation) in leaves with developing pustules (Fig. 3F). In contrast, the control plants showed reduced CsMAPK1 levels, particularly at $6 \mathrm{~h}$ postinfection, and no expression of the protein was detected in leaves with developing canker lesions (Fig. 3F).
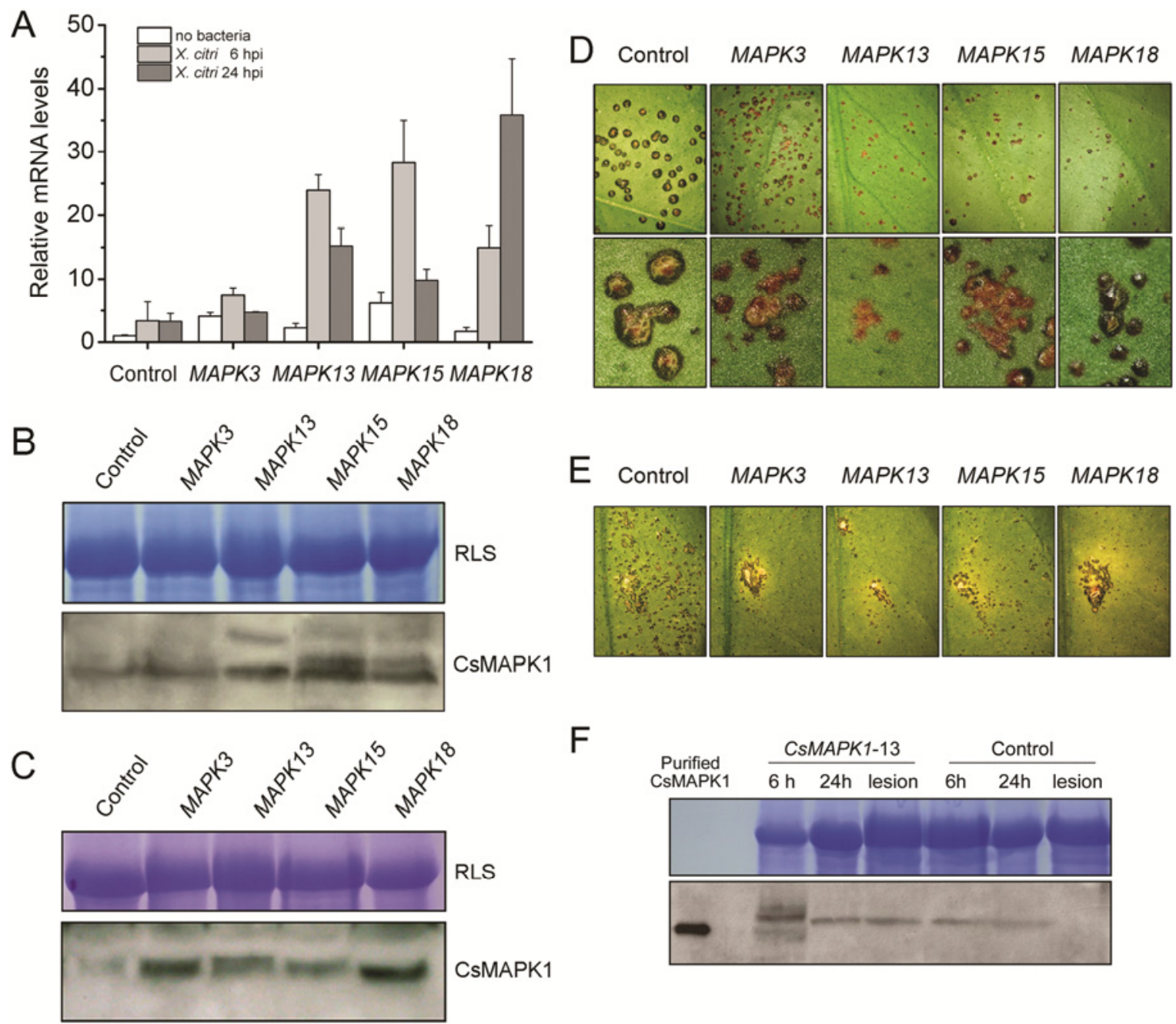

$\mathrm{F}$

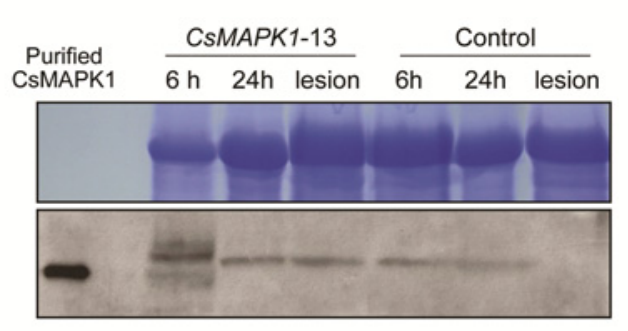

Fig. 3. Increased expression of CsMAPK1 correlates with increased resistance to Xanthomonas citri. A, Quantitative polymerase chain reaction analysis of CsMAPK1 expression in CsMAPK1 transgenic plants challenged with $X$. citri. Four independent CsMAPK1 transgenic plants $(3,13,15$, and 18) overexpress CsMAPK1 at 6 and $24 \mathrm{~h}$ after bacterial inoculation as compared with nontransformed plants (Control). Although the native CsMAPK1 promoter is induced by $X$. citri (Control), higher expression levels of the CsMAPK1 mRNA are driven by the PR 5 promoter in the transgenic plants at 6 and $24 \mathrm{~h}$ after bacterial inoculation. B, Western blot analysis of proteins extracted from leaves of control and transgenic plants $6 \mathrm{~h}$ after X. citri inoculation. The anti-CsMAPK1 serum detected increased levels of CsMAPK1 in the transgenic plants compared with control. Protein loads were controlled by Coomassie brilliant blue staining of the ribulose-1,5-bisphosphate carboxylase large subunit (RLS) bands (upper panel). C, Western blot analysis of control and transgenic plants $2 \mathrm{~h}$ after leaves had been wounded, showing higher levels of CsMAPK1 in the transgenic lines compared with control. Protein loads were controlled by Coomassie brilliant blue staining of the RLS bands (upper panel). D, Troyer leaves of control and transgenic plants that had been spray-inoculated with $X$. citri showing a reduction in canker symptoms in the transgenic lines (upper panel, 10× magnification; lower panel, 50× magnification). Pustules in the CsMAPK1 lines were reduced in number and size and showed an unusual morphology and pigmentation. E, Leaves of control and transgenic plants that had been infiltrated with a $X$. citri suspension (approximately $10^{3}$ cells), showing a yellowing of the infiltrated leaf sectors and a reduction in canker symptoms in the transgenic lines (10× magnification). F, Western blot analysis of leaves of CsMAPK1-13 and control plants inoculated with $X$. citri at different time intervals ( 6 and $24 \mathrm{~h}$ postinfection) and of leaves showing developing canker pustules (lesion). CsMAPK1 was expressed at higher levels $6 \mathrm{~h}$ postinfection in leaves of the CSMAPK1-13 line compared with the control. CsMAPK1 was also detected in leaves of the transgenic but not a control plant showing canker lesions. Protein loads were controlled by Coomassie brilliant blue staining of the RLS bands (upper panel). 
To examine whether the CsMAPK1 overexpression was interfering with the pathogen growth, we determined the bacterial population in leaves of transgenic and control plants infiltrated with $X$. citri suspensions of different cell densities. We noticed that even with a high bacterial density (approximately $10^{5}$ cells), which we had used to determine the exponential growth of $X$. citri in citrus plants (Cernadas et al. 2008), bacterial growth was significantly reduced in the transgenic relative to control plants from day 2 to day 14 postinoculation (Fig. 4A). In these experiments, bacterial populations in the transgenic leaves were, on average, 50 times lower than in the control leaves 14 days postinoculation (Fig. 4A). However, when we infiltrated a lower density of $X$. citri cells (approximately $10^{3}$ cells), the average bacterial growth determined at 2 and 14 days postinoculation were 100 and 700 times lower in the transgenic relative to control plants, respectively (Fig. 4B).

Collectively, these results emphasize the role of CsMAPK1 as an important component of the Citrus sinensis defense response against $X$. aurantifolii and it can also be effective against $X$. citri.

\section{CsMAPK1-mediated resistance}

against Xanthomonas correlates with ROS production.

Since multiple lines of evidence support the role of MAPK in ROS-mediated defense response against bacterial patho-


Fig. 4. Bacterial growth curves in leaves of control and transgenic Troyer plants expressing CsMAPK1. A, Leaves were infiltrated with approximately $0.1 \mathrm{ml}$ of a high-density suspension of bacterial cells (approximately $10^{6}$ cells per milliliter), and bacterial growth was followed daily by counting the number of bacterial cells retrieved from three independent infected leaves. B, Leaves of transgenic and control plants were infiltrated with approximately $0.1 \mathrm{ml}$ of a $10^{4}$ Xanthomonas citri cells-per-milliliter suspension, and the number of bacterial cells were determined at 2 and 14 days after inoculation. In both experiments, the growth of $X$. citri was significantly inhibited in the CsMAPK1 transgenic plants relative to untransformed plants (control). Asterisks in B indicate that the differences between the control and transgenic means are statistically significant at the $P<0.05$ level. gens, we sought to investigate a link between CsMAPK1 and ROS production (Jammes et al. 2009; Pitzschke et al. 2009; Sinha et al. 2011; Yoshioka et al. 2009). Therefore, we examined the accumulation of hydrogen peroxide on wounded areas of $C s M A P K$ transgenics lines using diaminobenzidine (DAB) staining (Thordal et al. 1997). We noticed an increased DAB activity in the tissues adjacent to the wounds in the transgenic plants at 2 and $6 \mathrm{~h}$ after the treatment relative to controls. In particular, stronger DAB stainings were detected in leaves of the CsMAPK1-13 line at $6 \mathrm{~h}$ after the wound (Fig. 5A).

The pattern of DAB staining around the wounded sites in the CsMAPK1 lines is reminiscent to that of GUS accumulation observed in the reporter plants (Fig. 2B), which indicates an overlapping between $C S M A P K 1$ expression and ROS production. To test whether CsMAPK1 is directly associated with a ROS-mediated defense response against $X$. aurantifolii in sweet orange leaves, we analyzed leaf tissues by DAB assays $24 \mathrm{~h}$ after bacterial infiltration. Consistently, the results revealed an increased DAB staining in the leaf sectors inoculated with $X$. aurantifolii relative to $X$. citri, which was only visible under high magnifications (Fig. 5B). In particular, DAB accumulation was more evident in the oil cells of tissues infiltrated with $X$. aurantifolii (Fig. 5B). These observations suggested to us that the ROS production of sweet orange 'Pera' in response to $X$. aurantifolii is a well-regulated stepwise process. This idea is partially supported by our microarray data and by the fact that the HR response to $X$. aurantifolii in this citrus variety is atypical, in the sense that cell death at the site of bacterial infiltration is not clearly visible (Cernadas et al. 2008). Thus, the higher accumulation of CsMAPK1 observed in the initial hours after $X$. aurantifolii infiltration (Fig. 1C) correlates with the local generation of hydrogen peroxide in response to this bacterium (Fig. 5B).

Since $X$. citri is able to suppress the host defense response (i.e., down-regulate the expression of defense-related genes) early after inoculation (Cernadas et al 2008), we asked whether $X$. citri have the ability to block the accumulation of hydrogen peroxide in the plants overexpressing CsMAPK1. We found that the leaf sectors of CsMAPK1-13 plants infiltrated with $X$. citri developed a stronger DAB staining compared with control plants (Fig. 5C), thereby supporting the role of CsMAPK1 during ROS production.

CsMAPK1 controls the expression of defense-related genes.

The relationship between CsMAPK1 overexpression and ROS production pointed us to test whether CsMAPK1 is regulating the expression of defense-related genes. Therefore, we analyzed the expression of five basal defense-related genes after wounding in CsMAPK1-13 plants. We selected genes encoding a PR1 protein and a WRKY factor induced by $X$. $a u$ rantifolii (Cernadas et al. 2008), a catalase similar to SPCAT1 (Chen et al. 2012) and a $S$-adenosyl-L-methionine-salicylic acid carboxyl methyltransferase (SAM-SACM) implicated in the synthesis of methyl salicylate (Negre et al. 2002). We used the CsCYP gene as a control because its expression is invariant during $X$. citri or $X$. aurantifolii infection (Fig. 1B). The results revealed that all five defense-related genes but not CsCYP were significantly induced by wounding in the CsMAPK1-13 line (Fig. 6A). In contrast, wounding treatment was not sufficient to induce significant expression changes of catalase, PR1, WRKY, or SAM-CM in plants used as controls. As expected, CsMAPK1 was induced by wounding in both the control and CsMAPK1-13 plants. However, its expression was consistently higher in the transgenic line, as described before (Figs. 1D and 3C). The citrus PRl and $W R K Y$ factor genes were also much strongly induced by wounding in the CsMAPK1-13 line than in control plants (Fig. 6). However, 
both the catalase and $S A M-S A C M$ genes were down-regulated in the control plants after wounding (Fig. 6A).

A similar pattern of defense gene activation, which is in accord with reported microarray data (Cernadas et al. 2008), was observed when control and CsMAPKI-13 plants were challenged with $X$. citri (Fig. 6B). Most notably, however, the expression of the catalase, PR1, and SAM-SACM genes, which were up-regulated by wounding, appeared to also be significantly induced by $X$. citri in the CsMAPK1-13 line, suggesting that CsMAPK1 might also be involved in SA metabolism (Fig. 6A).

Taken together, these results indicate that the ROS accumulation mediated by the CsMAPK1 is accompanied by a boost in the expression of basal defense response genes upon Xanthomonas infection.

\section{DISCUSSION}

\section{Dissecting the citrus defense response against Xanthomonas pathogens.}

Although many authors have reported the use of exogenous genes in transgenic citrus to increase disease resistance, more robust gene candidates are still lacking for canker resistance (Boscariol et al. 2006; Cardoso et al. 2009; Fu et al. 2011; Mendes et al. 2010; Yang et al. 2011; Zhang et al. 2010). For example, modulation of the citrus callose synthase (CalS1) and limonene synthase genes restrained the growth of $X$. citri in lemon and sweet orange plants, respectively. However, molecular mechanisms by which these genes provide partial resistance (or contribute to the resistance) against the bacterium were not described (Enrique et al. 2011; Rodríguez et al. 2011).

In this study, we present supporting evidences for the role of CsMAPK1 in the defense response against two citrus canker pathogens, $X$. citri and $X$. aurantifolii. The increased expression of CSMAPK1 driven by the inducible PR5 promoter in citrus leaves correlated with a decrease in canker development and pathogen growth (Figs. 3 and 4) as well as with the production of hydrogen peroxide and the transcriptional activation of defense-related genes (Figs. 5 and 6). As described above, we successfully used the Xanthomonas-induced $P R 5$ promoter to boost the CsMAPK1 overexpression, which was presumably suppressed by $X$. citri between 6 and $48 \mathrm{~h}$ after infiltration (Cernadas et al. 2008). Experiments performed in transgenic Troyer plants revealed that the protein accumulation of CsMAPK1 (Fig. 3B) was concomitant with the upregulation of defense-related genes, catalase, WRKY, SAM-SACM, and PR1 (Fig. 6). We conceive that these genes are important components of the citrus defense response, since they were also strongly up-regulated in the HR-like response of sweet orange leaves infiltrated with $X$. aurantifolii (Cernadas et al. 2008).

Phylogenetic analyses clustered CsMAPK1 in Group A of MAPK (Fig. 1) along with WIPK and SIPK, which were suggested to regulate the tomato defense response against Xanthomonas vesicatoria, as well as the SA levels of tobacco after wounding, thereby indicating a potential crosstalk between these MAPK and SA-signaling (Seo et al. 2007). Moreover, transcriptional analyses of the Arabidopsis mutants $m k k l$ and $m k k 2$ also support the interconnection between MAPK and SA accumulation, which also involves ROS production (Pitzschke et al. 2009). In particular, ROS synthesis appears to be an intrinsic mechanism of the Citrus-Xanthomonas defense response (Enrique et al. 2011). In agreement with this, we noticed increased hydrogen peroxide accumulations in the CsMAPK1 transgenic leaves challenged with $X$. citri (Fig. 5).

The nonhost defense response in Arabidopsis thaliana to $X$. citri is accompanied by the expression of defense genes, ROS generation, and synthesis of SA (An and Mou 2012). However, resistance appears to be compromised in the sid2/nprl double mutant, indicating a critical role of SA in the process (An and Mou 2012). Although we had found a link between CsMAPK1 signaling and ROS production, the only evidence for SA involvement was the strong induction of the citrus gene $S A M$ $C M$ by $X$. citri in the plants overexpressing $C s M A P K 1$, particularly in line 13 (Fig. 6). SAM-CM is a likely homolog of SAcarboxy-methyltransferase implicated in SA metabolism, reflecting the plausible relationship between CsMAPK1 induction and SA (Negre et al. 2002).

Based on these observations, we conclude that continuous and prolonged gene induction of CsMAPK1, as observed in response to $X$. aurantifolii or in PR5:CsMAPK1 transgenic plants infiltrated with $X$. citri, is an important signaling component of the citrus defense response involving defense genes induction, ROS synthesis, and plausible SA signaling, which needs further exploration.

\section{MEK2 kinase: A putatively conserved signaling cascade triggered by Xanthomonas spp.}

The tomato disease resistance against $X$. vesicatoria is mediated by a kinase cascade involving MEK2, which phosphorylates and activates WIPK and SIPK, resulting in the induction of defense genes and ROS production (Melech-Bonfil and Sessa 2010, 2011). We had identified the putative citrus MEK2 homo$\log$ (CsMEK2), which is also up-regulated in response to $X$. aurantifolii infiltration (Cernadas et al. 2008). This observation, in parallel with the larger levels of hydrogen peroxide accumulated in the CsMAPK1 transgenics, suggested to us that CsMAPK1 is targeted and activated by CsMEK2-mediated phosphorylation. Ongoing research is being addressed to test this hypothesis. However, and most interestingly, in some immunoblots, we detected extra bands of higher molecular weight at the early stages after bacterial infiltration, particularly in the transgenic lines (Fig. 3). We speculate that they may correspond with the phosphorylated forms of the CsMAPK1. Whether the CsMAPK1 requires activation via phosphorylation by CsMEK2 to initiate the defense response remains to be answered and will enlighten better strategies toward the generation of resistant citrus plants against Xanthomonas spp.

\section{The role of radical burst in canker resistance.}

The role of radical burst via MAPK signaling in plant immunity has been well documented (Asai and Yoshioka 2008; Yoshioka et al. 2009). In this work, we correlate the overexpression of CsMAPK1 with the increased resistance to X. citri, which appears to be mediated by the production of hydrogen peroxide and expression of defense-related genes. Particularly, we remark that the ROS toxicity to X. citri plays a fundamental role in defense and that Xanthomonas spp. are capable of tolerating the hydrogen peroxide generated by the host through the combined actions of xanthan gum and the expression of several antioxidant enzymes (Enrique et al. 2011; Kumar et al. 2011a and b; Tondo et al. 2010). This, in part, explains the low DAB staining observed in sweet orange leaves infiltrated with $X$. citri relative to $X$. aurantifolii (Fig. 5). Consistent with this, Fu and associates (2011) reported that the increased production of hydrogen peroxide in sweet orange overexpressing a spermidine synthase gene correlated with increased resistance to $X$. citri. In kumquat (Fortunella spp.), a citrus relative that is highly tolerant to citrus canker, the hydrogen peroxide turnover was suppressed during $X$. citri infection by the host expression of antioxidant enzymes (Kumar et al. 2011c and d). This is similar to what we observed in $X$. aurantifolii-infected sweet orange since $X$. citri-inoculated kumquat plants also overexpressed genes related to ROS scavenging, including superoxide dismutase, to preclude the oxidative damage over 
the infected leaf areas (Khalaf et al. 2011). Accordingly, the upregulation of a citrus catalase gene in the CsMAPK1-13 line in response to wounding or $X$. citri infiltration could be reflecting the response to counteract the hydrogen peroxide accumulation observed upon wounding and $X$. citri infiltration (Figs. 5 and 6). These results are, therefore, in agreement with previous studies, which suggested that the resistance against $X$. aurantifolii in sweet orange is mediated by a MAPK signaling cascade associated with ROS production and that $X$. citri, on the other hand, is able to suppress the defense response in the early stages of infection (Cernadas et al. 2008).

We conclude that these findings establish a correlation between CSMAPK1 expression, hydrogen peroxide accumulation, and defense-gene activation against $X$ citri in citrus plants. The modulation of ROS production in response to $X$. citri by using pathogen-induced promoters is a promising alternative to breed commercial citrus varieties resistant to the citrus canker disease.

\section{MATERIALS AND METHODS}

\section{Gene cloning and promoter fusions.}

The promoter of the Citrus sinensis PR5 gene was cloned by PCR from a genomic DNA library. Total DNA extracted from sweet orange leaves was partially digested with $S p h \mathrm{I}$, and fragments between 0.5 to $2 \mathrm{~kb}$ were gel-purified and subsequently ligated to adaptor A (TAATACGACTCACTATAGGGATCTG CACCAGAATTCCATG) containing the site for amplification with nested oligo A (GATCTGCACCAGAATTCCATG). Primers corresponding to the PR5 gene (CGAAAGTGGCTGCGTT
GACCC and AGCCCAGACCGTGTAGGGGC) were used in combination with adaptor and oligo $\mathrm{A}$ in nested $\mathrm{PCR}$ reactions to amplify sequences upstream of the start codon of the gene. A segment of approximately $400 \mathrm{bp}$ upstream of the start codon of the PR5 gene was amplified with oligos A and CCAT GGTGGCTATGTTTGGAGGGG and was ligated upstream of the initial ATG of the CsMAPK1 gene (accession JQ678766).

The CSMAPKl gene was amplified by reverse transcription (RT)-PCR from total RNA extracted from sweet orange leaves (Cernadas et al. 2008), using oligos CCATGGCTGACGTGGC GCAGGTC and CTCGAGTTAAGCAAATCCCGGATTGAG TGCTAATG, and was cloned into the NcoI/SacI sites of the pUC18 vector carrying the $P R 5$ promoter at the $5^{\prime}$ end. The $P R 5:: C S M A P K 1$ construct was subsequently subcloned into the binary vector pBI121 (HindIII/SacI) for Agrobacterium transformation. The same $P R 5$ promoter was also cloned into the HindIII/BamHI sites of pBI121 upstream of the uidA (GUS) gene to generate the control PR5::uidA. All constructs were verified by DNA sequencing and were transformed into the Agrobacterium tumefaciens EHA105 for plant transformation.

\section{Multiple-sequence alignments and phylogenetic analysis.}

Multiple sequence alignments of the deduced amino acid sequences of MAPK of citrus (CsMAPK1), Nicotiana tabacum (NtWIPK, Ntf4-2, and NtSIPK), and Arabidopsis thaliana (AtMAPK1-20) were generated, using the ClustalX program (version 2.0) (Larkin et al. 2007). The Arabidopsis and N. tabacum MAPK protein sequences were downloaded from The Arabidopsis Information Resource and National Center for Biotechnology Information, respectively. Phylogenetic trees


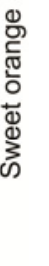

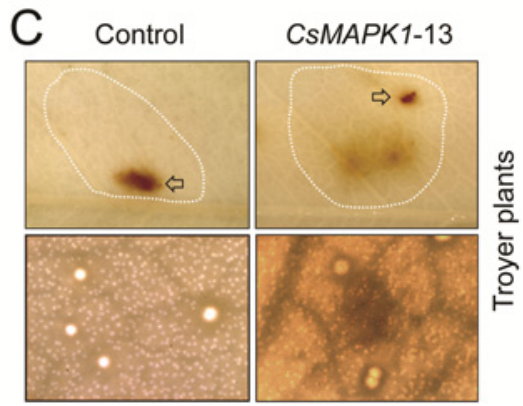

Fig. 5. CSMAPK1 plants accumulate hydrogen peroxide upon wounding. A, Leaves of control and transgenic Troyer plants expressing CsMAPK1 were wounded and were subjected to diaminobenzidine (DAB) staining for the presence of hydrogen peroxide. The histological detection of hydrogen peroxide was performed at 2 and $6 \mathrm{~h}$ after the wounding. Although control plants seem to accumulate hydrogen peroxide in response to wounding, the accumulation of hydrogen peroxide was more pronounced in the transgenic plants, particularly in the CsMAPK1-13 line, as judged by the intensity of the orange-brown pigmentation at the vicinity of the wounds. Increased DAB staining in response to wounding was observed in 10 of 10 transgenic leaves inspected. B, Histological detection of hydrogen peroxide (DAB staining) of sweet orange leaves infected with Xanthomonas citri or X. aurantifolii at $24 \mathrm{~h}$ postinoculation (dotted lines indicate the infiltrated leaf sectors). The upper panel, at 10× magnification, shows no significant differences between the two pathogens; however, at $50 \times$ magnification (lower panel), an orange-brownish color is primarily detected in the oil cells of tissues infiltrated with $X$. aurantifolii. C, Histological detection of hydrogen peroxide (DAB staining) in leaves of control and transgenic Troyer plants infected with $X$. citri during $24 \mathrm{~h}$ (dotted lines indicate the infiltrated leaf sectors). The upper panel, at 10× magnification, shows increased DAB staining in the infiltrated leaf sector of the transgenic plant compared with control. The increase in DAB staining in response to $X$. citri infection can be observed in more detail at 50× magnification (lower panel). Arrows in B and $\mathrm{C}$ indicate the site of pinprick inoculation. The pattern of differential DAB staining shown in B and C was observed in seven of 10 leaf sectors inspected outside the pinprick site. 
were constructed using the MEGA 4.1 program (Tamura et al. 2007) with the neighbor-joining method (Saitou and Nei 1987) and bootstrap resampling analysis (1,000 replicates).

\section{Plant transformation and bacteria infiltration.}

Epicotyls of Troyer citrange plants were transformed with the Agrobacterium strains carrying the PR5::CsMAPK1 or $P R 5::$ uidA constructs, as previously described (de Oliveira et al. 2009). The explants selected under kanamycin resistance were propagated in culture medium and, subsequently, were transplanted onto soil and maintained in a greenhouse under natural light regime with temperatures varying from 18 to $35^{\circ} \mathrm{C}$ and relative humidity ranging from 50 to $70 \%$.

Plants were infiltrated with water suspensions of $X$. citri or $X$. aurantifolii pathotype $\mathrm{C}$ previously grown in LBON plates (Luria Bertani [LB] without $\mathrm{NaCl}$ ), supplemented with ampicillin (100 mg per liter), for $48 \mathrm{~h}$ at $28^{\circ} \mathrm{C}$ (Cernadas et al. 2008). Approximately $0.1 \mathrm{ml}$ of $10^{5}$ or $10^{6}$ cells per milliliter was infiltrated on each fully expanded leaf. Also, the lower side of the leaves was sprayed with a bacterial suspension of $10^{6}$ cells per milliliter. Plants were monitored daily for the appearance of canker symptoms.

\section{Histochemical GUS assays.}

GUS activity in leaves of three independent two-year-old PR5::uidA reporter plants was detected by colorimetric assays at different time intervals after wounding or bacterial infiltration (Jefferson et al. 1987). Leaves detached from plants were immediately immersed into the GUS buffer $(50 \mathrm{mM}$ sodium phosphate, $10 \mathrm{mM}$ EDTA, 0,1\% sarkosyl, 0,1\% Triton X-100, $10 \mathrm{mM}$ 2-mercaptoethanol, $1 \mathrm{mM} \mathrm{X}$-Gluc), were incubated at $37^{\circ} \mathrm{C}$ overnight in the dark, and were subsequently destained with $70 \%$ ethanol.

\section{Bacterial growth assays.}

The growth of $X$. citri in leaves of control and transgenic plants expressing CsMAPK1 were evaluated as previously described (Cernadas et al. 2008). Briefly, disks of leaf sectors that had been infiltrated with approximately $10^{5} \mathrm{X}$. citri cells were removed daily and were ground in $1 \mathrm{ml}$ of sterile water. Serial dilutions of the bacterial suspensions were plated on LBON with ampicillin at $100 \mathrm{mg}$ per liter. Individual bacterial colonies or colony-forming units were counted from three independent leaf extractions.

\section{Protein expression and antibody production.}

The coding sequence of CsMAPK1 was subcloned into pET28a ( NdeI/SacI) vector using the oligos CATATGGCTGA CGTGGCGCAGGTC and CTCGAGTTAAGCAAATCCCGG ATTGAGTGCTAATG, and were subsequently transformed into Escherichia coli BL21 (DE3) cells for protein expression. Cells were grown at $37^{\circ} \mathrm{C}$ in LB supplemented with kanamy$\operatorname{cin}(50 \mu \mathrm{g} / \mathrm{ml})$ to an optical density at $600 \mathrm{~nm}=0.6$, followed by induction with $0.4 \mathrm{mM}$ isopropyl- $\beta$-D-thiogalactoside for $3 \mathrm{~h}$. Cells were harvested by centrifugation, were suspended in binding buffer $(20 \mathrm{mM}$ Tris- $\mathrm{HCl}, \mathrm{pH} 8.0,300 \mathrm{mM} \mathrm{NaCl}, 5$ $\mathrm{mM}$ imidazole), and were incubated on ice with lysozyme (1.0 $\mathrm{mg} / \mathrm{ml}$ ) and sonicated. Clarified supernatants containing the 6xHis-CsMAPK1 fusion protein were loaded on a HiTrap chelating HP column (GE Healthcare, Piscataway, NJ. U.S.A.). Fractions were eluted with an imidazole gradient, and concentrated. purified CsMAPK1 (approximately $1 \mathrm{mg}$ ) was used to immunize rabbits for antiserum production.

\section{CsMAPK1 detection in plant cell extracts.}

Sweet orange and Troyer leaves of six- and 24-month-old plants, respectively, were infiltrated with a suspension of $X$. citri or X. aurantifolii $\left(10^{4}\right.$ cells), and were collected for Western blot analysis at 6 and $24 \mathrm{~h}$ after bacterial inoculation. Sweet orange leaves were also wounded with a scalpel and were collected for analysis at 2 and $6 \mathrm{~h}$ after the wounding. Leaves were ground to powder in liquid nitrogen and were suspended in sodium dodecyl sulfate-polyacrylamide gel electrophoresis (SDS-PAGE) sample buffer. The suspension was heated for 5 min at $90^{\circ} \mathrm{C}$, and cell debris and insoluble materials were separated by centrifugation at $14,000 \times g$, and the soluble fractions were analyzed in $8 \%$ SDS-PAGE gels and were subsequently transferred onto nylon membranes for Western blot detection. Blots were incubated with the anti-CsMAPK1 serum at 1:500 dilution and were developed by chemiluminescence.
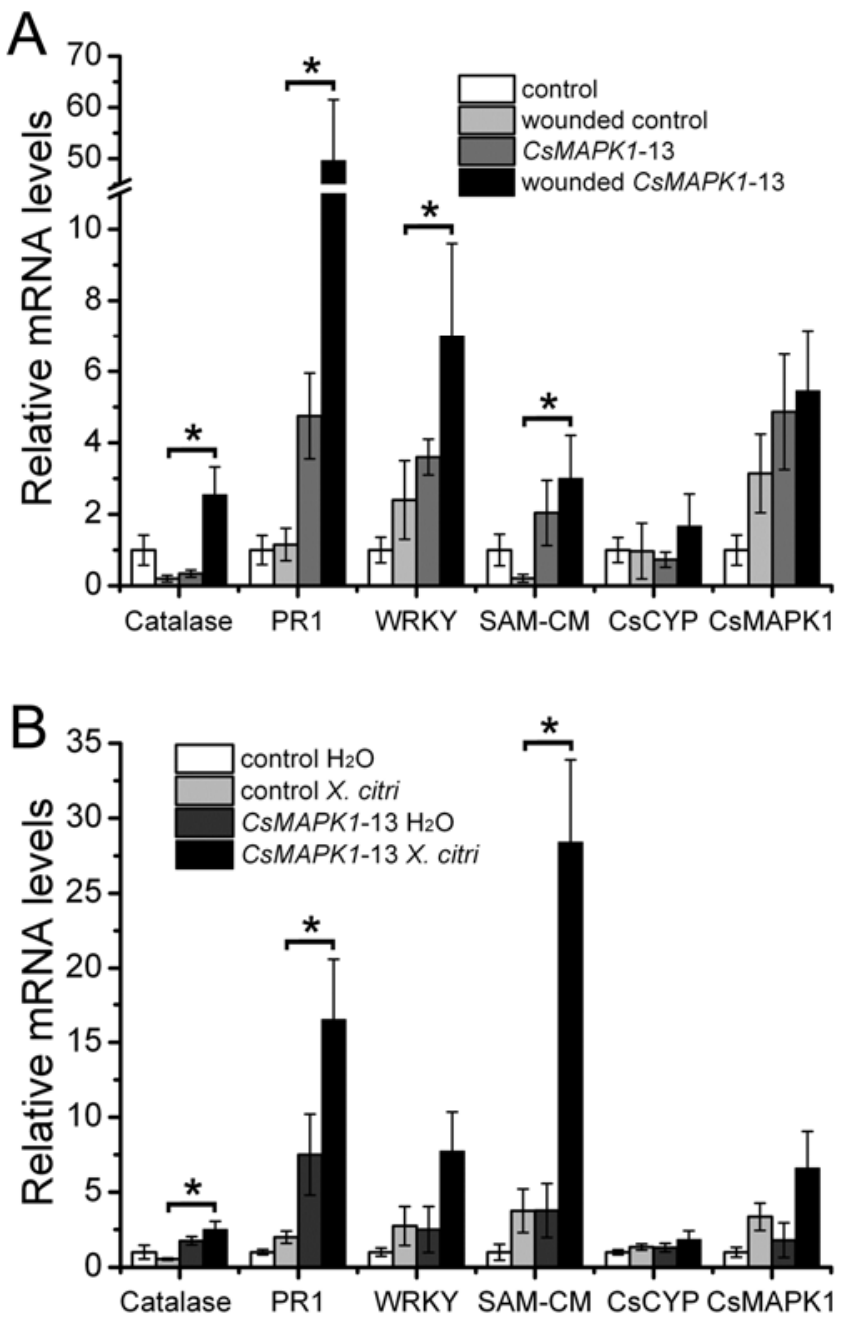

Fig. 6. CsMAPK1-13 plants show increased expression of defenserelated genes. A, Relative fold-change expression levels by quantitative reverse-transcription polymerase chain reaction of CSMAPK1 and four additional defense-related genes (catalase, PRI, WRKY, and SAM$S A C M$ ) in the CSMAPK1-13 transgenic and control plants, in response to wounding. The CsCYP gene, whose expression does not vary between the transgenic and control, was used as reference. Bars represent fold change of mRNA abundance in leaves of CsMAPK1-13 or control plants at $3 \mathrm{~h}$ after wounding. B, Relative fold change expression levels of catalase, PR1, WRKY, SAM-SACM, CsCYP, and CsMAPK1 genes in $C s M A P K 1-13$ and control plants at $48 \mathrm{~h}$ after $X$. citri infiltration. Leaves were infiltrated with a suspension of $10^{6}$ cells per milliliter or water as control. In panels $\mathrm{A}$ and $\mathrm{B}$, the fold change values are normalized with 'control' and 'control $\mathrm{H}_{2} \mathrm{O}$ ' samples, respectively, and a malate translocator (accession CF834784) as internal control for equal cDNA inputs. Error bars denote standard deviations, and asterisks indicate statistically significant differences between control and transgenic leaves of at least three biological replicates $(P<0.05)$. 


\section{Hydrogen peroxide detection in plant tissues.}

Hydrogen peroxide was detected in plant tissues using the DAB method (Thordal et al. 1997). Young leaves of Troyer plants were wounded with a scalpel, and after 2 and $6 \mathrm{~h}$, leaves were vacuum-infiltrated for 10 min with a solution of $0.5 \mathrm{mg}$ of DAB per milliliter in $20 \mathrm{mM}$ sodium acetate, $\mathrm{pH} 3.8$. Leaves were maintained in the DAB solution overnight at room temperature in the dark and were discolored with $100 \%$ ethanol for visualization.

Sweet orange and Troyer leaves infiltrated with a suspension of X. citri or X. aurantifolii $\left(10^{4}\right.$ cells) were collected after 24 $\mathrm{h}$ and were placed in the DAB buffer, as described above. The orange brownish color observed in the examined tissues indicates the accumulation of hydrogen peroxide (Thordal et al. 1997).

\section{Assays of semiquantitative and quantitative RT-PCR.}

Total RNA was extracted from leaves of control and transformed Troyer citrange plants, using Trizol reagent (Invitrogen, Carlsbad, CA, U.S.A.) and treating with DNase I (Promega, Madison, WI, U.S.A.). Nearly $10 \mu \mathrm{g}$ of total RNA was reversetranscribed using the SuperScript synthesis system (Invitrogen), and cDNAs were used as templates in the semiquantitative and quantitative PCR analysis.

Semiquantitative PCR were performed, using standard amplification mixtures containing $1.5 \mathrm{mM} \mathrm{MgCl} 2,200 \mu \mathrm{M}$ each dNTP, $2.0 \mu \mathrm{l}$ of cDNA, 2 U Taq DNA polymerase, and 0.25 $\mu \mathrm{M}$ primers in a $50 \mu \mathrm{l}$ final volume. Amplification reactions were conducted in the following conditions: 1 cycle at $94^{\circ} \mathrm{C}$ for 4 min, followed by 25 cycles of 1 min denaturation at $94^{\circ} \mathrm{C}$ for $1 \mathrm{~min}, 1.5 \mathrm{~min}$ annealing at $55^{\circ} \mathrm{C}$ for the $C s C Y P$ gene (accession $\mathrm{ACX} 37092)$ or $57^{\circ} \mathrm{C}$ for the CsMAPK1 gene, and $1 \mathrm{~min}$ elongation at $72^{\circ} \mathrm{C}$.

SYBR green real-time quantitative PCR was performed in 96-well reaction plates in an ABI Prism 7300 (Applied Biosystems, Foster City, CA, U.S.A.). Primer sequences corresponding to the Citrus sinensis genes CsMAPK1, PR1 (accession CF653559), WRKY (Citrus Genome Database code orange1.1g019404m), Catalase (accession CX671534), and SAM-SACM (accession CN182915) were designed using the Primer Express 2.0 software (Applied Biosystems). Each 25- $\mu$ l reaction mixture contained $12.5 \mu \mathrm{l}$ of SYBR green $2 \times$ master mix (Applied Biosystems), $1 \mu \mathrm{l}$ of forward and reverse primer $\operatorname{mix}(7.5 \mu \mathrm{M}), 1 \mu \mathrm{l}$ of cDNA, and $10.5 \mu \mathrm{l}$ of diethyl pyrocarbonate-treated water. Amplifications were carried out for $2 \mathrm{~min}$ at $50^{\circ} \mathrm{C}$ and $10 \mathrm{~min}$ at $95^{\circ} \mathrm{C}$, followed by 40 amplification cycles of $15 \mathrm{~s}$ at $95^{\circ} \mathrm{C}$ and $1 \mathrm{~min}$ at $60^{\circ} \mathrm{C}$. The Citrus sinensis gene encoding a malate translocator (accession CF834784) was chosen as an internal control for normalization. Total RNA from three different leaves were used in the real-time PCR reactions as independent biological replicates.

\section{ACKNOWLEDGMENTS}

We thank financial support from Fundação de Amparo à Pesquisa do Estado de São Paulo (Fapesp) and Conselho Nacional de Desenvolvimento Científico e Tecnológico (CNPq). M. L. P. de Oliveira and C. E. Benedetti received fellowships from Fapesp and $\mathrm{CNPq}$, respectively.

\section{LITERATURE CITED}

An C., and Mou Z. 2012. Non-host defense response in a novel ArabidopsisXanthomonas citri subsp. citri pathoystem. PLoS One 7:e31130. Published online.

Asai, S., and Yoshioka, H. 2008. The role of radical burst via MAPK signaling in plant immunity. Plant Signal Behav. 3:920-922.

Boscariol, R. L., Chabregas, S. M., Vieira, M. L. C., Pereira, L. F. P. P., Vieira, L. G. E., Bergamin Filho, A., Barbosa, J. M., Azevedo, F. A., Mourão-Filho, F. A. A., and Mendes, B. M. J. 2006. Attacin A gene from Tricloplusia ni reduces susceptibility to Xanthomonas axonopodis pv. citri in transgenic Citrus sinensis cv. Hamlin. J. Amer. Soc. Hort. Sci. 131:530-536.

Brunings, A. M., and Gabriel, D. W. 2003. Xanthomonas citri: Breaking the surface. Mol. Plant Pathol. 4:141-157.

Cardoso, S. C., Barbosa-Mendes, J. M., Boscariol-Camargo, R. L. Christiano, R. S. C., Bergamin Filho, A., Vieira, M. L. C., Mendes, B. M. J., and Mourão Filho, F. A. A. 2009. Transgenic sweet orange (Citrus sinensis L. Osbeck) expressing the attacin A gene for resistance to Xanthomonas citri subsp. citri. Plant Mol. Biol. Rep. 28:185-192.

Cernadas, R. A., and Benedetti, C.E. 2009. Role of auxin and gibberellin in citrus canker development and in the transcriptional control of cellwall remodeling genes modulated by Xanthomonas axonopodis pv. citri. Plant Sci. 177:190-195.

Cernadas, R. A., Camillo, L. R., and Benedetti, C. E. 2008. Transcriptional analysis of the sweet orange interaction with the citrus canker pathogens Xanthomonas axonopodis pv. citri and Xanthomonas axonopodis pv. aurantifolii. Mol. Plant Pathol. 9:609-631.

Chen, H. J., Wu, S. D., Huang, G. J., Shen, C. Y., Afiyanti, M., Li, W. J., and Lin, Y. H. 2012. Expression of a cloned sweet potato catalase SPCAT1 alleviates ethephon-mediated leaf senescence and $\mathrm{H}_{2} \mathrm{O}_{2}$ elevation. J. Plant Physiol. 169:86-97.

Chisholm, S. T., Coaker, G., Day, B., and Staskawicz, B. J. 2006. Hostmicrobe interactions: Shaping the evolution of the plant immune response. Cell 124:803-814.

de Oliveira, M. L. P., Febres, V. J., Costa, M. G. C., Moore, G. A., and Otoni, W. C. 2009. High-efficiency Agrobacterium-mediated transformation of citrus via sonication and vacuum infiltration. Plant Cell Rep. 28:387-395.

Enrique, R., Siciliano, F., Favaro, M. A., Gerhardt, N., Roeschlin, R., Rigano, L., Sendin, L., Castagnaro, A., Vojnov, A., and Marano, M. R. 2011. Novel demonstration of RNAi in citrus reveals importance of citrus callose synthase in defense against Xanthomonas citri subsp. citri. Plant Biotechnol. J. 9:394-407.

Fu, X-Z., Chen, C-W., Wand, Y., Liu, J-H., and Moriguchi, T. 2011. Ectopic expression of MdSPDS1 in sweet orange (Citrus sinensis OsbecK) reduces canker susceptibility: Involvement of $\mathrm{H}_{2} \mathrm{O}_{2}$ production and transcription alteration. BMC Plant Biol. 11:55.

Galletti, R., Ferrari, S., and De Lorenzo, G. 2011. Arabidopsis MPK3 and MPK6 play different roles in basal and oligogalacturonide- or flagellininduced resistance against Botrytis cinerea. Plant Physiol. 157:804-14.

Huang, X. S., Luo, T., Fu, X. Z., Fan, Q. J., and Liu, J. H. 2011. Cloning and molecular characterization of a mitogen-activated protein kinase gene from Poncirus trifoliata whose ectopic expression confers dehydration/drought tolerance in transgenic tobacco. J Exp Bot. 62:51915206

Ishihama, N., Yamada, R., Yoshioka, M., Katou, S., and Yoshioka, H. 2011. Phosphorylation of the Nicotiana benthamiana WRKY8 transcription factor by MAPK functions in the defense response. Plant Cell 23:1153-1170.

Jammes, F., Song, C., Shin, D., Munemasa, S., Takeda, K., Gu, D., Cho, D., Lee, S., Giordo, R., Sritubtim, S., Leonhardt, N., Ellis, B. E., Murata, Y., and Kwak, J. M. 2009. MAP kinases MPK9 and MPK12 are preferentially expressed in guard cells and positively regulate ROS-mediated ABA signaling. Proc. Natl. Acad. Sci. U.S.A. 106:20520-20525.

Jefferson, R. A., Kavanagh, N-H., and Bevan, M. W. 1987. GUS fusions: $\beta$-glucuronidase as a sensitive and versatile gene fusion marker in higher plants. EMBO (Eur. Mol. Biol. Organ.) J. 6:3901-3907.

Jonak, C., Kiegerl, S., Ligterink, W., Barker, P. J., Huskisson, N. S., and Hirt, H. 1996. Stress signaling in plants: A mitogen-activated protein kinase pathway is activated by cold and drought. Proc. Natl. Acad. Sci. U.S.A. 93:11274-11279.

Jones, J. D. G., and Dangl, J. L. 2006. The plant immune system. Nature 444:323-329

Khalaf, A. A., Gmitter, F. G. Jr., Conesa, A., Dopazo, J., and Moore, G. A. 2011. Fortunella margarita transcriptional reprogramming triggered by Xanthomonas citri subsp. citri. BMC Plant Biol. 11:159.

Kumar, N., Ebel, R. C., and Roberts, P. D. 2011a. Antioxidant metabolism of grapefruit infected with Xanthomonas axonopodis pv. citri. Environ. Exp. Bot.71:41-49.

Kumar, N., Ebel, R. C., and Roberts, P. D. 2011b. $\mathrm{H}_{2} \mathrm{O}_{2}$ metabolism during sweet orange (Citrus sinensis L. Osb.) "Hamlin" Xanthomonas axonopodis pv. citri interaction. Sci. Hort. 128:465-472.

Kumar, N., Ebel, R. C., and Roberts, P. D. 2011c. $\mathrm{H}_{2} \mathrm{O}_{2}$ is suppressed in kumquat leaves infected with Xanthomonas axonopodis pv. citri. Sci Hort. 130:241-247.

Kumar, N., Ebel, R.C., and Roberts, P. D. 2011d. Superoxide dismutase activity in kumquat infected with Xanthomonas axonopodis pv. citri. J. Hort. Sci. Biotechnol. 86:62-68.

Larkin, M. A., Blackshields, G., Brown, N. P., Chenna, R., McGettigan, P. 
A., McWilliam, H., Valentin, F., Wallace, I. M., Wilm, A., Lopez, R., Thompson, J. D., Gibson, T. J., and Higgins, D. G. 2007. Clustal W and Clustal X version 2.0. Bioinformatics 23:2947-2948.

Ligterink, W., Kroj, T., zur Nieden, U., Hirt, H., and Scheel, D. 1997. Receptor-mediated activation of a MAP kinase in pathogen defense of plants. Science 276:2054-2057.

Liu, X., Bai, X., Wang, X., and Chu, C. 2007a. OsWRKY71, a rice transcription factor, is involved in rice defense response. J. Plant Physiol. 164:969-979

Liu, Y., Ren, D., Pike, S., Pallardy, S., Gassmann, W., and Zhang, S. 2007b. Chloroplast-generated reactive oxygen species are involved in hypersensitive response-like cell death mediated by a mitogen-activated protein kinase cascade. Plant J. 51:941-954.

MAPK Group. 2002. Mitogen-activated protein kinase cascades in plants: A new nomenclature. Trends Plant Sci. 7:301-308.

Melech-Bonfil, S., and Sessa, G. 2010. Tomato MAPKKKe is a positive regulator of cell-death signaling networks associated with plant immunity. Plant J. 64:379-391.

Melech-Bonfil, S., and Sessa, G. 2011. The SIMKK2 and S1MPK2 genes play a role in tomato disease resistance to Xanthomonas campestris pv. vesicatoria. Plant Signal Behav. 6:154-156.

Mendes, B. M. J., Cardoso, S. C., Boscariol-Camargo, R. L., Cruz, R. B., Mourão Filho, F. A. A., and Bergamin Filho, A. 2010. Reduction in susceptibility to Xanthomonas axonopodis pv. citri in transgenic Citrus sinensis expressing the rice $X a 21$ gene. Plant Pathol. 59:68-75.

Mizoguchi, T., Irie, K., Hirayama, T., Hayashida, N., Yamaguchi-Shinozaki, K., Matsumoto, K., and Shinozaki, K. 1996. A gene encoding a mitogenactivated protein kinase kinase kinase is induced simultaneously with genes for a mitogen-activated protein kinase and an S6 ribosomal protein kinase by touch, cold, and water stress in Arabidopsis thaliana. Proc Natl Acad Sci U.S.A. 93:765-9.

Negre, F., Kolosova, N., Knoll, J., Kish, C. M., and Dudareva, N. 2002. Novel $S$-adenosyl-L-methionine: Salicylic acid carboxyl methyltransferase, an enzyme responsible for biosynthesis of methyl salicylate and methyl benzoate, is not involved in floral scent production in snapdragon flowers. Arch. Biochem. Biophys. 406:261-270.

Oh, S. K., Yi, S. Y., Yu, S. H., Moon, J. S., Park, J. M., and Choi, D. 2006. CaWRKY2, a chili pepper transcription factor, is rapidly induced by incompatible plant pathogens. Mol. Cells 22:58-64.

Pitzschke, A., Djamei, A., Bitton, F., and Hirt, H. 2009. A major role of the MEKK1-MKK1/2-MPK4 pathway in ROS signalling. Mol. Plant 2:120-137.

Ren, D., Yang, H., and Zhang, S. 2002. Cell death mediated by MAPK is associated with hydrogen peroxide production in Arabidopsis. J. Biol. Chem. 277:559-565.

Ren, D., Yang, K. Y., Li, G. J., Liu, Y., and Zhang, S. 2006. Activation of $\mathrm{Ntf} 4$, a tobacco mitogen-activated protein kinase, during plant defense response and its involvement in hypersensitive response-like cell death. Plant Physiol. 141:1482-1493.

Rodriguez, M. C. S., Petersen, M., and Mundy, J. 2010. Mitogen-activated protein kinase signaling in plants. Annu. Rev. Plant Biol.61:621-649.

Rodríguez, A., San Andrés, V., Cervera, M., Redondo, A., Alquézar, B., Shimada, T., Gadea, J., Rodrigo, M. J., Zacarías, L., Palou, L., López,
M. M., Castañera, P., and Peña, L. 2011. Terpene down-regulation in orange reveals the role of fruit aromas in mediating interactions with insect herbivores and pathogens. Plant Physiol. 156:793-802.

Saitou, N., and Nei, M. 1987. The Neighbor-Joining method: A new method for reconstructing phylogenetic trees. Mol. Biol. Evol. 4:406425.

Seo, S., Okamoto, M., Seto, H., Ishizuka, K., Sano, H., and Ohashi, Y. 1995. Tobacco MAP kinase: A possible mediator in wound signal transduction pathways. Science 270:1988-1992.

Seo, S., Katou, S., Seto, H., Gomi, K., and Ohashi, Y. 2007. The mitogenactivated protein kinases WIPK and SIPK regulate the levels of jasmonic and salicylic acids in wounded tobacco plants. Plant J. 49:899-909.

Sinha, A. K., Jaggi, M., Raghuram, B., and Tuteja, N. 2011. Mitogen-activated protein kinase signaling in plants under abiotic stress. Plant Signal Behav. 6:196-203.

Takahashi, Y., Nasir, K. H., Ito, A., Kanzaki, H., Matsumura, H., Saitoh, H., Fujisawa, S., Kamoun, S., and Terauchi, R. 2007. A high-throughput screen of cell-death-inducing factors in Nicotiana benthamiana identifies a novel MAPKK that mediates INF1-induced cell death signaling and non-host resistance to Pseudomonas cichorii. Plant J. 49:10301040 .

Tamura, K., Dudley, J., Nei, M., and Kumar, S. 2007. MEGA4: Molecular evolutionary genetics analysis (MEGA) software version 4.0. Mol. Biol. Evol. 24:1596-1599.

Thordal Christensen, H., Zhang, Z. G., Wei, Y. D., and Collinge, D. B. 1997. Subcellular localization of $\mathrm{H}_{2} \mathrm{O}_{2}$ in plants. $\mathrm{H}_{2} \mathrm{O}_{2}$ accumulation in papillae and hypersensitive response during the barley-powdery mildew interaction. Plant J. 11:1187-1194

Tondo, M. L., Petrocelli, S., Ottado, J., and Orellano, E. G. 2010. The monofunctional catalase KatE of Xanthomonas axonopodis pv. citri is required for full virulence in citrus plants. PLoS One 5:e10803. Published online.

Vilela, B., Pagès, M., and Lumbreras, V. 2010. Regulation of MAPK signaling and cell death by MAPK phosphatase MKP2. Plant Signal Behav. 5:1497-1500.

Yang, L., Hu, C., Li, N., Zhang, J., Yan, J., and Deng, Z. 2011. Transformation of sweet orange [Citrus sinensis (L.) Osbeck] with pthA-nls for acquiring resistance to citrus canker disease. Plant Mol. Biol. 75:11-23.

Yoshioka, H., Asai, S., Yoshioka, M., and Kobayashi, M. 2009. Molecular mechanisms of generation for nitric oxide and reactive oxygen species, and role of the radical burst in plant immunity. Mol. Cells 28:321-329.

Zhang, X., Francis, M. I., Dawson, W. O., Graham, J. H., Orbović, V., Triplett, E. W., and Mou, Z. 2010. Over-expression of the Arabidopsis NPR1 gene in citrus increases resistance to citrus canker. Eur. J. Plant Pathol. 128:91-100.

\section{AUTHOR-RECOMMENDED INTERNET RESOURCES}

Arabidopsis Information Resourcewebsite: www.arabidopsis.org National Centre for Biotechnology Information website: www.ncbi.nlm.nih.gov 